\title{
FLORES DE METAL: PROYEGTO DE CO-CREAGIÓN DE AUDIOVISUALES PARA LA PREVENCIÓN DEL MALTRATO A LA MUJER
}

\author{
METAL FLOWERS: AUDIOVISUAL CO-CREATION \\ PROJEGT TO PREVENT WOMEN MISTREATMENT
}

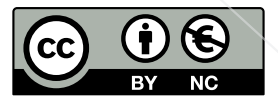

\author{
Gregorio Enrique Puello-Socarrás \\ Universitaria Virtual Internacional
}

Colombia

Se graduó como Diseñador Industrial de la Universidad Nacional de Colombia, posee estudios como Administrador de Empresas y de especialización en Pedagogía para la Docencia Universitaria de la Fundación Universitaria del Área Andina, es especialista en Gerencia en Riesgos Laborales, Seguridad y Salud en el Trabajo de la Corporación Universitaria Minuto de Dios; así mismo es Magister en Gerencia y Práctica del Desarrollo de la Universidad de los Andes (Colombia), se ha desempeñado como investigador docente en notables procesos de investigación formativa con diferentes reconocimientos a nivel institucional, amplia experiencia en proyectos de investigación, publicaciones científicas y procesos de innovación social desde el diseño y la administración. Sus líneas de investigación principales son Diseño y Desarrollo Social; Desarrollo e innovación social; Gestión social, participación y desarrollo comunitario; además de Educación, Transformación social e Innovación. Actuó dentro del proyecto como investigador principal y director del programa de producción gráfica publicitaria de la Fundación Tecnológica Autónoma de Bogotá y es ahora docente del área de investigaciones de la Universitaria Virtual Internacional.

ge.puello10@uniandes.edu.co

gpuello@gmail.com

orcid.org/0000-0001-7507-5937 


\section{Axel Rodríguez Peña \\ Universitaria Virtual Internacional \\ Colombia}

Es diseñador gráfico de la UDI - Universidad de Investigación y Desarrollo de la ciudad de Bucaramanga (Colombia), Magíster en Diseño Gráfico Digital de la Universidad de La Rioja (España), notable productor de contenidos digitales y análogos a nivel institucional y multimedia y coinvestigador en proyectos de investigación sobre Diseño y Desarrollo Social. Amplia trayectoria docente y asesoría temática con reconocimientos importantes en las áreas de Diseño y desarrollo social. Actuó como Director de la Escuela de Artes y Humanidades - Fundación Tecnológica Autónoma de Bogotá y es ahora docente del programa de Diseño Gráfico de la Universitaria Virtual Internacional.

arodrgezp@uvirtual.edu.com

orcid.org/0000-0003-4249-6123

\section{Camilo Ernesto Villota Pascuaza \\ Universitaria Virtual Internacional \\ Colombia}

Es diseñador gráfico de la Universidad de Nariño de la ciudad de Pasto (Colombia), Especialista en Gerencia de Multimedia de la Universidad Santo Tomás, Magister en Visual Communication Bath Spa University (Reino Unido) notable productor de proyectos de diseño y desarrollo comunitario, a través de contenidos digitales y análogos a nivel institucional y multimedia; investigador y coinvestigador en proyectos de investigación sobre Diseño y Desarrollo Social. Amplia trayectoria docente y reconocimientos importantes en las áreas de Diseño Social; Cultura y Patrimonio; Diseño Sociedad y Cultura. Es ahora docente y coordinador de investigación del programa de Diseño Gráfico de la Universitaria Virtual Internacional.

cevillotap@uvirtual.edu.co

orcid.org/0000-0003-4461-9182

Fecha de recepción: 16 de mayo, 2019. Aceptación: 20 de mayo, 2020 


\section{Resumen}

El proyecto Flores de Metal aborda el problema de la comunicación desde la perspectiva gráfica en temáticas sociales. El objetivo de este proyecto, consistió en desarrollar herramientas educativas audiovisuales abordando la problemática del maltrato a la mujer en una institución educativa y su comunidad incorporando metodologías de innovación social y co-creación. No se desarrolla hipótesis al inicio de la investigación, por ser un proceso de marcado enfoque cualitativo donde las variables son vistas en su contexto de forma holística, como expresan Hernández, Fernández y Baptista (2016), pero esta se enuncia al momento de realizar las conclusiones. Para este cometido se escoge una muestra no probabilística de conveniencia, por tratarse de una población con características de acceso restringido (menores de edad). Se realiza un estudio transversal; utilizando para la comprensión de los conocimientos y actitudes frente al tema por parte de los actores, los instrumentos de recolección de datos diario de campo y cartografía social. Luego inicia el proceso de co-creación que es el punto de inflexión principal de la investigación-creación, como mencionan Puello-Socarrás \& Rodríguez (2017). El resultado son tres recursos audiovisuales, generados en conjunto con los talleristas, donde se instalan capacidades de realización audiovisual y reflexiones sobre temas de desarrollo humano que potencian las temáticas de contenido social no solo en los talleristas sino también en las comunidades de influencia, proponiendo una nueva discusión y un cambio social en los actores.

\section{Palabras clave}

Creación, obras visuales, comunicación verbal y visual, narrativa, investigación-creación.académica.

\section{Abstract}

The Metal Flowers project addresses the problem of communication from the graphic perspective in social issues. The objective of this project was to develop educational audiovisual tools addressing the issue of abuse of women in an educational institution and its community by incorporating social innovation and co-creation methodologies. No hypothesis was developed at the beginning of the research, as it was a process with a marked qualitative focus where the variables were seen in their context in a holistic way, as expressed by Hernández, Fernández and Baptista (2016), but this was stated at the time of making the conclusions. For this task, a non-probabilistic sample of convenience was chosen, since it is a population with restricted access characteristics (minors). A cross-sectional study was carried out, using daily field data collection instruments and social mapping to understand the knowledge and attitudes of the actors. Then the co-creation process began, which was the main turning point of research-creation, as mentioned by Puello-Socarrás \& Rodríguez (2017). The result was three audiovisual resources, generated jointly with the workshop participants, where audiovisual production capacities and reflections on human development issues were installed, which enhanced social content issues not only in the workshop participants but also in the communities of influence, proposing a new discussion and social change in the actors.

\section{Keywords}

Creation, visual works, verbal and visual communication, narrative, creative research. 


\section{Introducción}

Los derechos humanos y más puntualmente los derechos de la mujer han sido vulnerados a través de la historia en forma permanente. De acuerdo con lo planteado por la Organización Mundial de la Salud (WH0-OMS), en su sitio web, se ha identificado a partir de diversos estudios:

Las estimaciones más precisas relativas a la prevalencia de la violencia de pareja y la violencia sexual se derivan de las encuestas poblacionales basadas en los testimonios de las víctimas. En un análisis llevado a cabo en 2013 por la OMS en colaboración con la Escuela de Higiene y Medicina Tropical de Londres y el Consejo de Investigación Médica de Sudáfrica, en el que se utilizaron los datos de más de 80 países, se observó que, en todo el mundo, una de cada tres mujeres (o el 35\%) había sido objeto de violencia física o violencia sexual bien dentro o fuera de la pareja (OMS, 2017).

Y más adelante menciona como factores de riesgo lo presentado en la tabla 1:

Tabla 1. Factores de riesgo para la violencia y el maltrato contra la mujer

\section{Factor de riesgo}

Bajo nivel de instrucción

Historial de exposición al maltrato infantil

\begin{tabular}{ll}
\hline Experiencia de violencia familiar & Autores y víctimas \\
\hline Trastorno de personalidad antisocial & Autores \\
\hline Uso nocivo del alcohol & Autores y víctimas \\
\hline $\begin{array}{l}\text { Tener muchas parejas o de inspirar sospechas de } \\
\text { infidelidad en la pareja }\end{array}$ & Autores \\
\hline Actitudes que toleran la violencia & Autores \\
\hline $\begin{array}{l}\text { Existencia de normas sociales que privilegian a los } \\
\text { hombres o les atribuyen un estatus superior y } \\
\text { otorgan un estatus inferior a las mujeres }\end{array}$ & Sociedad \\
\hline $\begin{array}{l}\text { Acceso reducido de la mujer a empleo remunerado. } \\
\text { Sociedad }\end{array}$
\end{tabular}

Autores de violencia sexual y víctimas de violencia sexual

Autores y víctimas

\section{Actor}


Lo anterior es un reflejo de que el problema constituye un complejo entramado que afecta la salud pública a nivel global, así como el desarrollo humano, la realización ética del ser y el ejercicio y disfrute de la ciudadanía plena, puesto que enajena a la mujer de su dignidad humana y coarta la garantía y satisfacción de sus derechos como ser humano y como persona.

La misma Organización Mundial de la Salud plantea en este escenario algunas estrategias sugeridas para promover el cambio social necesario en la sociedad frente a este problema, que para este caso indica que:

Cada vez hay más estudios bien concebidos sobre la eficacia de los programas de prevención y respuesta. Se necesitan más recursos que refuercen la prevención y la respuesta frente a la violencia de pareja y la violencia sexual, en particular en el ámbito de la prevención primaria, a fin de impedir que llegue a producirse (OMS, 2017).

En este contexto, el proyecto Flores de Metal, concebido desde el programa de Diseño Gráfico Publicitario y como iniciativa institucional de la Fundación Tecnológica Autónoma de Bogotá, en conjunto con la Universidad de Santander en su sede Bogotá (Colombia), aborda este problema desde la perspectiva de la comunicación gráfica y enfocado en tres ejes fundamentales: la investigación-creación, los procesos de cambio e innovación social y el ejercicio del diseño como disciplina llamada a tener un puesto especial en el desarrollo humano. Para ello se apoya en la recomendación explícita de la OMS, que indica:

Entre las estrategias de prevención que podrían dar buenos resultados en entornos de bajos recursos cabe citar las siguientes: aquellas que (...) fomentan la comunicación y las relaciones interpersonales dentro de la pareja y la comunidad (...) las que transforman las normas sociales y de género nocivas, mediante la movilización de la comunidad y la educación grupal y participativa de mujeres y hombres con el fin de provocar una reflexión crítica sobre las relaciones de género y de poder desiguales (OMS, 2017).

En este punto, vale la pena aclarar que, por un lado, esta situación va más allá de ser un problema sólo para las mujeres y por otro, que no sólo se manifiesta desde el aspecto de violencia física o sexual, sino que, en el contexto colombiano, posee manifestaciones de violencia psicológica-emocional y económica-patrimonial.

A nivel nacional, según el Observatorio de Violencia del Instituto Nacional de Medicina Legal y Ciencias Forenses en el año 2017, se denunciaron a nivel nacional 59.639 casos documentados de violencia contra la mujer, de los cuales 6.924 fueron con mujeres menores de 18 años y 52.715 fueron con mayores de 18 años, incluyendo adultas mayores. De las anteriores, 19.424 agresiones fueron realizadas por el compañero permanente (INMLCF, 2017).

Es necesario indicar que estos datos corresponden a denuncias documentadas, sin considerar el subregistro u omisión de denuncia, que podría ser mucho mayor. Bogotá y Cundinamarca corresponden a los territorios más afectados por la problemática según los reportes de esta institución oficial.

Para ser catalogada como víctima de violencia debe presentar algún tipo de maltrato, ya sea físico, emocional, sexual entre otros. Es importante anotar que este no es un problema de un solo sector de la sociedad, se da en todas las capas sociales, en todos los niveles de intensidad y con igual crueldad, indistintamente de la posición social, geográfica y sociodemográfica de las víctimas. En un estudio desarrollado por la CEPAL, ya en 1996 se advertía de esta situación: 
La violencia de género puede adoptar diversas formas, lo que permite clasificar el delito, de acuerdo con la relación en que ésta se enmarca y el ejercicio de poder que supone, en las siguientes categorías: violación sexual e incesto, asedio sexual en el trabajo y en las instituciones de educación, violencia sexual contra mujeres detenidas o presas, actos de violencia contra las mujeres desarraigadas, tráfico de mujeres y violencia doméstica (Rico, 1996, p. 5).

Por lo tanto, se identifica a partir de esta lectura el fenómeno del maltrato a la mujer como un problema de vulneración de los derechos humanos, transversal, perenne y en algunos casos estructural de las sociedades, que requiere esfuerzos superiores y constantes para ser erradicado y de esta manera restablecer el derecho, conforme los estados nacionales deben garantizarlo.

Ahora bien, reconocer, clasificar y proyectar investigación sobre las causas, manifestaciones, consecuencias y posibles escenarios para la atención y exploración de las soluciones educativas respecto al problema del maltrato a la mujer, es el propósito que reunió un conjunto de profesionales interdisciplinares de las áreas del Diseño y de la Salud que trabajaron en los grupos de investigación FABArtes Social Enterprise, y Healthcare and Quality desde el año 2013, sobre la construcción de iniciativas vinculando actores comunitarios en los procesos de investigación y aplicación de las estrategias que desarrollaron los grupos de investigación.

Por último, el proyecto de investigación Flores de Metal buscó desarrollar herramientas audiovisuales enfocadas en la reflexión y cambio social a través de la instalación de capacidades gráficas desde la investigación-creación y el desarrollo humano. De esta manera, el desarrollo de medios audiovisuales incide en que la comunicación fuese clara y efectiva, generará un impacto en la comunidad y contribuyera en la formación integral estableciendo nuevos canales de comunicación que reflejen la voz de los actores y sus aprendizajes adquiridos.

\section{Desarrollo}

\section{Planteamiento del problema}

Según Menacho (2006), la violencia es tan vieja como el mundo, está vinculada a los orígenes, evolución y desarrollo del hombre, por tanto, es un concepto inherente a la humanidad. En este orden de ideas $y$, por otra parte, la comunicación, en palabras de Frascara (2000) plantea que "toda percepción es un acto de búsqueda de significado, $y$, en este sentido, es un acto de comunicación o de búsqueda de comunicación" (p. 61).

En cuanto a los derechos humanos, existe una preocupación significativa a nivel mundial debido a su tendencia creciente; la incorporación de este tema en la agenda de diversos foros de las naciones unidas ha sido muy significativo.

Hasta 1980 fue que se manifestó esta gran preocupación en la Conferencia Mundial del Decenio de las Naciones Unidas para la mujer; que tenía como fin la igualdad, desarrollo y paz, se desarrolló en Copenhague, en la cual se establece que el maltrato era un delito intolerable contra la dignidad de la mujer y que era un problema serio y muy complejo (ONU MUJERES, 2019).

Estos esfuerzos a nivel internacional, han resultado en diversos programas de acción para atención, prevención e investigación sobre el maltrato a la mujer, que incorporan la herramienta comunicacional como punta de lanza en la construcción de imaginarios sociales diferentes y puntos de diálogo social.

Para concluir, la violencia como fenómeno permea varias capas sociales y no tiene distingos de raza, religión, condición socioeconómica. En pocas palabras, la violencia es un problema del desarrollo humano que requiere toda la atención y la mejor forma de desarrollar una estrategia efectiva alrededor de este escenario se construye a partir del siguiente cuestionamiento: ¿De qué forma las capacidades de 
comunicación de los actores comunitarios pueden ser potenciadas desde los conceptos de investigación-creación, innovación social y diseño con sentido humano con el fin de promover la reflexión y el cambio social de la problemática del maltrato a la mujer?

Como objetivo principal del proyecto, se tuvo el desarrollar herramientas educativas audiovisuales acordes a la problemática del maltrato a la mujer en instituciones educativas de media vocacional, instituciones públicas prestadoras de salud y comunidades de un municipio de Colombia por medio del método de co-creación y procesos de innovación social.

\section{Antecedentes}

En la búsqueda de referentes se encontraron múltiples tipos de protestas y alertas que abordan el maltrato a la mujer o violencia de género. La primera área abordada fue la música, donde se encontraron canciones en las que sus intérpretes son una voz para concienciar y sensibilizar a sus oyentes de esta cuestión de tan alto impacto en la sociedad actual. Ante la multiplicidad de obras y narrativas visuales presentes frente al tema del maltrato, luego de realizados algunos estudios preliminares se encontró que entre los recordados por los investigadores y los involucrados en el proceso de co-creación, se establecieron como los más reconocidos por parte de los investigadores y participantes de la investigación y como punto de partida de las reflexiones:

- Malo - Bebe

- Ana Tijoux - Antipatriarca

- Valiente - Pimpinela

- Y en tu ventana - Andy y Lucas

- El peso del alma, Mago de OZ.

Otra área tenida en cuenta en la búsqueda fue el séptimo arte, puesto que desde los filmes es mucho más fácil identificar todo lo que va sucediendo en la medida que pasa el tiempo en la vida de una mujer que es violentada, desde el inicio de una red de mentiras, humillaciones, golpes, abusos, gritos y palabras que destruyen vidas. Algunas de las películas que abordan el tema y que de la misma manera fueron identificadas como punto de partida de las experiencias investigativas por parte de los investigadores y de los participantes de los talleres por igual fueron:

- "Los sobornados" dirigida por Fritz Lang en 1953

- "La pianista" dirigida por Michael Haneke en 2001

- "Te doy mis ojos" dirigida por la española Iciar Bollaín en 2003

- "La teta asustada" dirigida por Claudia Llosa en 2009.

Estos filmes, si bien corresponden a esfuerzos de relatos inéditos y poco conocidos, al ser compartidos al inicio por los investigadores y talleristas, permitieron compartir las experiencias audiovisuales y ponerlas en común, dejando al esfuerzo personal de cada uno de los participantes el tenerlos como fuente de consulta y referente para las experiencias posteriores y para los ejercicios de producción audiovisual.

\section{Campañas publicitarias}

De las campañas que han sido desarrolladas por distintas asociaciones, marcas y sociedades, se tomaron las siguientes piezas gráficas como referentes ya que en ellas se exponen diferentes ideas de maquillaje, vestuario y accesorios que pudiesen ser usadas en el ejercicio de construcción posterior de elementos e ideas de desarrollo de la investigación-creación:

- Alberta: Corresponde a una Entidad Gubernamental de la provincia de Alberta (Canadá) que brinda atención de servicios humanos contra el abuso, la violencia contra la mujer y el bullying. Entre las reflexiones más interesantes sobre las piezas desarrolladas por la campaña, entre investigadores y talleristas, se identifica la forma en que estos participantes reconocen que "dejan ver la manera en la que el hombre subyuga a la mujer, a la vez que la mujer deja ver tristeza en su expresión y es callada 
por la mano de un hombre quien no le permite dar a conocer su situación" (Puello-Socarrás \& Rodríguez, 2017b, p. 22).

- Fédération Nationale Solidarité Femmes: Es la federación francesa que apoya a la mujer que ha sido víctima de la violencia doméstica. Los talleristas e investigadores manifiestan, entre otras cosas: "La campaña muestra la imagen de un hombre con apariencia de un hombre correcto pero que por dentro guarda una bestia que agrede con violencia a su esposa o pareja" (Puello-Socarrás \& Rodríguez, 2017b, p. 24).

- APAV (Asociación de Prevención y Asistencia de la Violencia): La psicóloga Ana María Rocco lidera esta asociación ayudando a proteger los derechos humanos contra la agresión llevando su lema "Todos podemos vivir sin violencia". La reacción de talleristas e investigadores frente a las piezas se define de la siguiente manera: "La calidad de sus piezas es tan fuerte que causa una reflexión instintiva al problema" (Puello-Socarrás \& Rodríguez, 2017b, p. 25) lo cual es importante puesto que se identifican procesos de pensamiento y de irreflexión en las piezas gráficas para su uso posterior en la experiencia.

- Sahabat: es una asociación que ayuda y apoya a las mujeres víctimas de agresión, algunas de sus piezas visuales más significativas fueron realizadas por la productora gráfica Gina Virginia. Entre las percepciones generales de los participantes, encontramos que identifican que "la productora inspirada en un concepto diferente al tradicional, transformó a hombres con apariencias físicas muy rudas y quería darnos a entender que si las mujeres se vieran así los agresores seguirían violentándolas" (Puello-Socarrás \& Rodríguez, 2017b, p. 27).

- RI coalition against domestic violence: es una agencia que rechaza totalmente el maltrato y lo lleva a piezas que demuestran, en palabras de los talleristas e investigadores participantes: "que las mujeres pueden ser vistas por el hombre como un pedazo de carne 0 un saco de arena de entrenamiento que tan solo se pueden golpear sin razón alguna" (Puello-Socarrás \& Rodríguez, 2017b, p. 28).

- Usa la razón, que la música no degrade tu condición: Fue una de las campañas más reconocidas del 2014, en palabras de uno de los talleristas, desarrollada por la estudiante de fotografía Linely Ibáñez, quien quiso mostrar literalmente las canciones de reconocidos artistas del reggaetón en Colombia. De esta experiencia se identifica que: "con su crudo manejo fotográfico y contextualización real de las letras del género de música logró varios de sus objetivos" (Puello-Socarrás \& Rodríguez, 2017b, p. 31) en la reflexión sobre el maltrato.

Estas campañas en su momento generaron alto impacto en el público, que permitieron movilizar de una manera distinta y en diferentes partes del mundo la narrativa del maltrato a la mujer. Cabe recordar que la búsqueda de estos referentes se realizó con el propósito de realizar una búsqueda sistemática de referentes, sino más bien con el ánimo de identificar referentes en el imaginario de los participantes, por lo que la "randomización" de sus procedencias obedecen a la construcción de una narrativa desde los actores más que de procesos sistemáticos de investigación.

\section{Marco legal}

A raíz de cada caso en que se ha visto involucrada a una mujer, se han ido creando diferentes leyes de carácter educativo y formativo para cambiar su trato en diferentes ámbitos y la relación de poder que por años el hombre ha ejercido sobre éstas. Con estas leyes se pretende sensibilizar a la sociedad para incrementar la cultura de la denuncia, ya que se considera que los ciudadanos deben asumir la corresponsabilidad y que tienen el poder de denunciar cualquier caso del que tengan conocimiento. Hoy en día existen reglas o leyes consignadas en la Constitución, que cobijan a las mujeres e intentan garantizar su protección, algunas de ellas fueron relevantes 
para el ejercicio de reflexión colectiva sobre la garantía de protección estatal para el maltrato, previo a la construcción del material audiovisual, entre ellas se resaltan:

- Decreto 1930 del 6 de septiembre de 2013, por el cual se adopta la Política Pública Nacional de Equidad de Género y se crea una Comisión Intersectorial para su implementación.

- Ley 1639 del 2 de julio de 2013, por medio de la cual se fortalecen las medidas de protección a la integridad de las víctimas de crímenes con ácido.

- Decreto 164, 25 de enero de 2010, por el cual se crea una Comisión Intersectorial denominada "Mesa Interinstitucional para Erradicar la Violencia contra las Mujeres".

- Ley 1257, 4 de diciembre de 2008, por la cual se dictan normas de sensibilización, prevención y sanción de formas de violencia y discriminación contra las mujeres.

- Ley 1009, 23 de enero de 2006, por la cual se crea con carácter permanente el observatorio de asuntos de género.

- Ley 823, 11 de julio de 2003, por la cual se dictan normas sobre igualdad de oportunidades para las mujeres.

- Ley 731, 14 de enero de 2002, la presente ley tiene por objeto mejorar la calidad de vida de las mujeres rurales, priorizando las de bajos recursos y consagrar medidas específicas encaminadas a acelerar la equidad entre el hombre y la mujer rural.

- Ley 294, 16 de julio de 1996, por la cual se desarrolla el artículo 42 de la Constitución Política y se dictan normas para prevenir, remediar y sancionar la violencia intrafamiliar.

- Ley 82, 3 de noviembre de 1993, por la cual se expiden normas para apoyar de manera especial a la mujer cabeza de familia.

Es importante mencionar que una de las principales reflexiones del grupo investigador frente a la normativa mencionada consiste en manifestar que si bien el interés y los esfuerzo del Estado en garantizar la protección en especial de la mujer por su condición de vulnerabilidad es apreciable en años recientes, no es suficiente, ya que en muchas ocasiones la legislación no se conoce en su espíritu y alcances por parte de las comunidades de interés, con lo que se valida nuevamente la estrategia de apropiación social del conocimiento derivada de la integración del Diseño Gráfico Tecnológico como un factor crucial para comunicar estos alcances y conocer más a fondo las expectativas de los grupos humanos frente a estos desarrollos, lo que promueva el restablecimiento de derechos de los grupos y personas involucradas.

\section{Método}

El proceso de investigación-creación fue llevado a cabo a través de talleres focales desarrollados en varias sesiones con cortos períodos de tiempo de separación y enfocados en el desarrollo de los procesos de análisis necesarios, expresados en momentos del desarrollo multimedia, desde la identificación de antecedentes y narrativas hasta los procesos de producción y post-producción, y finalmente el lanzamiento de los cortometrajes.

En un primer momento del trabajo de campo, se desarrolla la exploración a través de la cartografía social y se exponen los resultados a los demás colaboradores. Se consigna el análisis y la experiencia a través de un storyline o guión literario, para posteriormente desarrollar a partir del mismo un guión técnico, que defina las tomas y planos necesarios para el desarrollo del audiovisual por parte de los talleristas. De una manera más general y como parte del proceso de planeación, el equipo investigador desarrolla la estrategia proyectual por fases, como se identifica a continuación y en la tabla 2.

El proyecto se implementó a partir de los referentes de la investigación acción participativa y metodología de investigación social y co-creación. Está estructurado en cinco fases donde se contemplaron las siguientes: 
Fase 1. Lectura de realidades y establecimiento de línea base de las capacidades iniciales para la co-creación de las herramientas audiovisuales.

Esta fase preliminar tuvo como escenarios el espacio universitario de la Fundación Tecnológica Autónoma de Bogotá, donde 14 participantes entre estudiantes y académicos plasmaron sus ejercicios investigativo-creativos en talleres formales e informales para la reflexión sobre el maltrato, sus espacios de clase y diferentes actividades lúdicas, como los salones de diseño que se realizaban semestralmente con el apoyo de la Coordinación de Diseño Gráfico Publicitario para mostrar los desarrollos desde las diferentes asignaturas del programa, siempre alrededor del tema del maltrato y las inquietudes de los estudiantes y la comunidad frente al tema. Posteriormente se realizaron los talleres de producción audiovisual con más de 30 estudiantes de bachillerato de una institución educativa del municipio de Sibaté (Cundinamarca - Colombia), cómo se presentará en la sección de resultados de este artículo.

Fase 2. Co-creación comunitaria para el desarrollo de los elementos básicos de la herramienta audiovisual.

Fase 3. Desarrollo tecnológico de la herramienta audiovisual.

Fase 4. Socialización de la herramienta educativa audiovisual a los diversos grupos de interés.

Fase 5. Evaluación y sistematización de todo el proceso con la participación activa de los diversos grupos de interés.
Estas fases se realizaron con los talleristas de la institución educativa del municipio de Sibaté (Cundinamarca - Colombia) y en las fases posteriores se integraron académicos y personalidades relevantes en el tema del maltrato como problema de salud pública en Colombia, los resultados se describen con detalle en la sección de resultados de este artículo.

Otros aspectos importantes del artículo comprenden los siguientes elementos:

- Población: Más de 50 talleristas estudiantes de una Institución Educativa del municipio de Sibaté (Cundinamarca - Colombia) y de Diseño Gráfico Publicitario de la Fundación Tecnológica Autónoma de Bogotá.

- Muestra: No probabilística - Por conveniencia

- Tipo de estudio planeado: Transversal

- Enfoque: Cualitativo

- Tipo de investigación: Estudio de casos / Investigación-creación

- Instrumentos de recolección de datos: Entrevista, Cartografía Social, Talleres de Innovación Social con incorporación de procesos multimedia, Diario de Campo.

- Instrumentos de análisis de datos: Informe de resultados de investigación, Storyline, Storyboard

- Productos creativos derivados de la experiencia hasta el momento: Tres (3) cortometrajes, una (1) estrategia de apropiación social del conocimiento, un (1) taller creativo de producción audiovisual, dos (2) ponencias internacionales y un (1) Artículo de resultado de investigación. 
Tabla 2. Fases de desarrollo del proyecto Flores de Metal

\begin{tabular}{|c|c|c|c|}
\hline Fase & Actividad & \multicolumn{2}{|c|}{ Resultado esperado } \\
\hline $\begin{array}{l}\text { Lectura de } \\
\text { Realidades }\end{array}$ & $\begin{array}{l}\text { Caracterización } \\
\text { participativa sobre } \\
\text { el maltrato a la } \\
\text { mujer }\end{array}$ & $\begin{array}{l}\text { Investigación- acción } \\
\text { participativa } \\
\text { Innovación social }\end{array}$ & $\begin{array}{l}\text { Lectura de realidad } \\
\text { sobre el maltrato a la } \\
\text { mujer (insumo para la } \\
\text { siguiente fase) }\end{array}$ \\
\hline $\begin{array}{l}\text { Co-creación } \\
\text { comunitaria }\end{array}$ & $\begin{array}{l}\text { Construcción de } \\
\text { guion literario y } \\
\text { story board } \\
\text { (preproducción) }\end{array}$ & Co-diseño & $\begin{array}{l}\text { Guiones literarios y } \\
\text { storyboard de las } \\
\text { herramientas educati- } \\
\text { vas audiovisuales }\end{array}$ \\
\hline $\begin{array}{l}\text { Desarrollo } \\
\text { tecnológico }\end{array}$ & $\begin{array}{l}\text { Producción } \\
\text { Edición } \\
\text { Sonorización } \\
\text { Prototipado }\end{array}$ & Diseño multimedia & $\begin{array}{l}\text { Prototipo de las } \\
\text { herramientas educati- } \\
\text { vas audiovisuales }\end{array}$ \\
\hline Socialización & $\begin{array}{l}\text { Campañas, } \\
\text { talleres educati- } \\
\text { vos y foro de la } \\
\text { mujer, entre otras }\end{array}$ & $\begin{array}{l}\text { Empoderamiento } \\
\text { comunitario }\end{array}$ & $\begin{array}{l}\text { Apropiación social del } \\
\text { conocimiento }\end{array}$ \\
\hline $\begin{array}{l}\text { Evaluación y } \\
\text { sistematización }\end{array}$ & $\begin{array}{l}\text { Análisis de línea } \\
\text { de base, contraste } \\
\text { y cierre } \\
\text { Desarrollo de } \\
\text { productos de } \\
\text { comunicación del } \\
\text { conocimiento }\end{array}$ & $\begin{array}{l}\text { Investigación creación } \\
\text { Innovación Social } \\
\text { Productos del Modelo } \\
\text { de SNCTel }\end{array}$ & $\begin{array}{l}\text { Artículos } \\
\text { Eventos científicos }\end{array}$ \\
\hline
\end{tabular}

\section{Resultados}

\section{i. Fase de lectura de capacidades inicia- les de la comunidad para la co-creación de las herramientas audiovisuales}

En esta primera sesión contó con más de 30 participantes realizadores de los audiovisuales, escogidos en los cursos de bachillerato de una Institución Educativa del municipio de Sibaté (Cundinamarca -
Colombia) se realizó una introducción general y una exploración-inventario de las necesidades y capacidades de los talleristas, lo anterior se desarrolló utilizando dos herramientas de investigación, la observación estructurada y una cartografía social, con el fin de obtener datos importantes de base sobre la percepción de los participantes acerca del Maltrato en su entorno social, al finalizar la sesión se realiza una exposición por grupos establecidos por los participantes. 
Los resultados de esta cartografía y su socialización fueron tenidos en cuenta en los procesos subsiguientes del taller para la elaboración de los cortometrajes. Los talleristas describieron las diferentes situaciones de maltrato a la mujer en su comunidad, basados en la discusión de ideas y plasmándolas en la cartografía.
Paralelamente, se realizó el foro de reflexión sobre el maltrato, en la sede principal de la Fundación Tecnológica Autónoma de Bogotá - FABA, por medio del cual se buscaba establecer una reflexión y una línea de base sobre el maltrato como parte del proceso de establecimiento de elementos clave que pudieran ser articulados con el taller como un espacio de co-creación, en las imágenes 1-3 se puede ver parte de este ejercicio:

Figura 1. Invitación digital enviada a los participantes para establecer una línea de base sobre la percepción de Maltrato en el nivel académico, que permitiera enriquecer la discusión y la creación de los productos gráficos
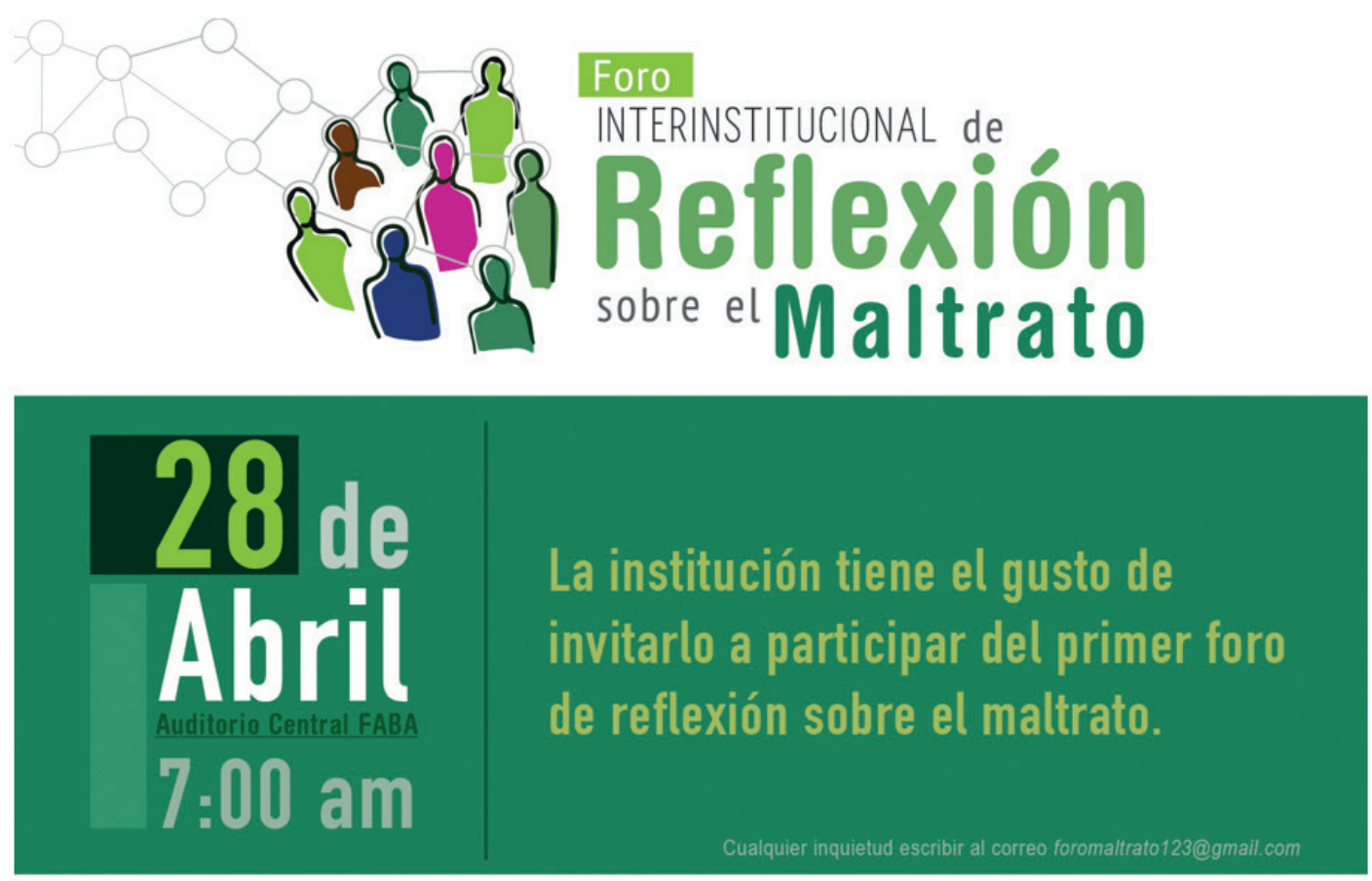

Invitan:

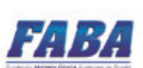

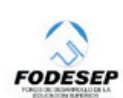
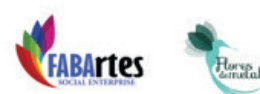

Aliados:

lospisingos

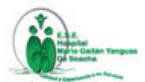


En esta oportunidad, se sumaron algunas instituciones relevantes a nivel institucional del orden nacional y que son referentes en torno a diferentes tipos de maltrato. Al establecer contacto con las instituciones que decidieron participar de esta convocatoria, se pudo comprender de primera mano la actualidad en el tema del maltrato desde diferentes actores y expertos, lo que permitió además a los investigadores actualizarse en el tema y prepararse para afrontar desde una mirada informada, el proceso de co-creación con la comunidad de talleristas.

Figura 2. Instalación foro de reflexión sobre el maltrato

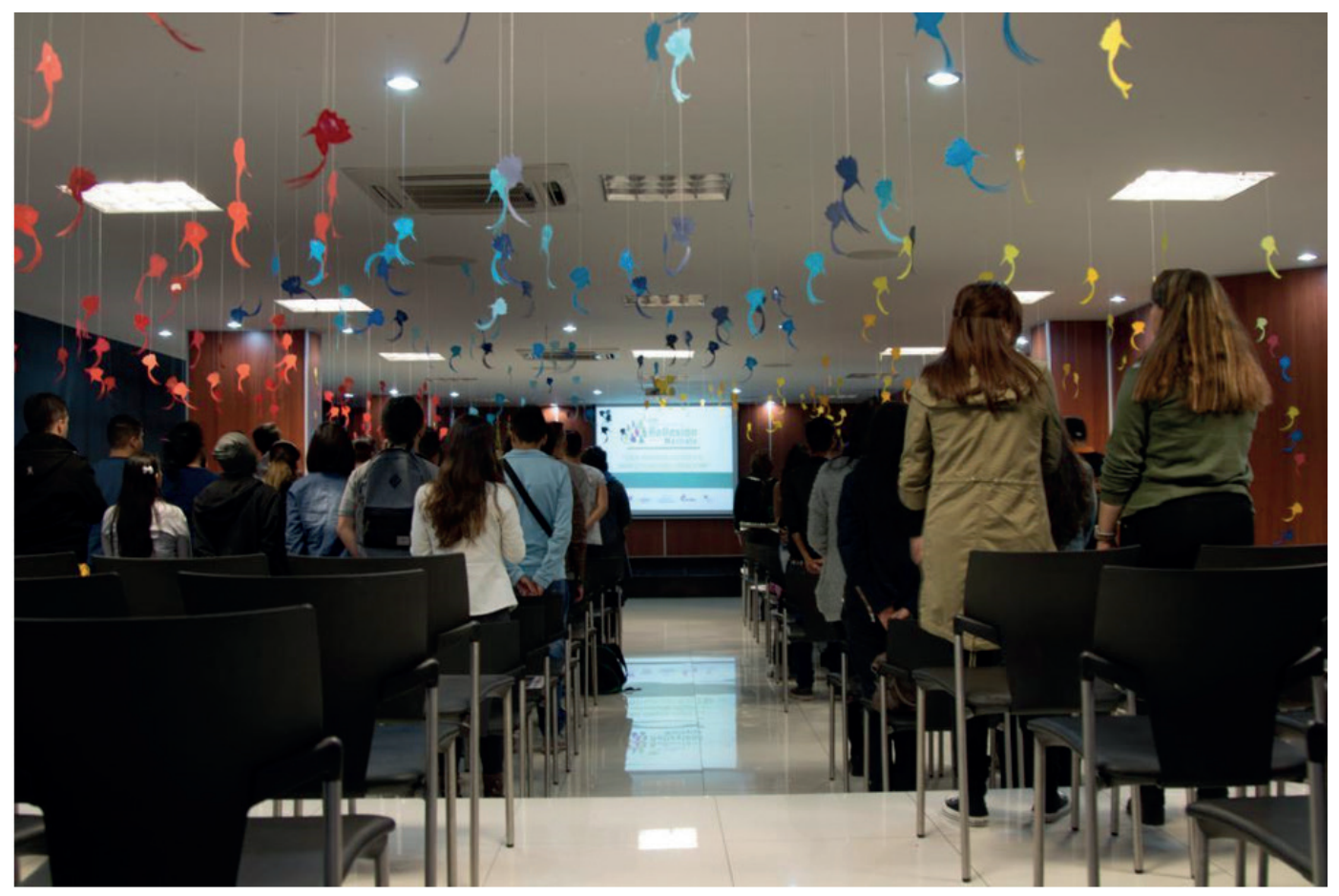


Figura 3. Performance de reflexión sobre el maltrato

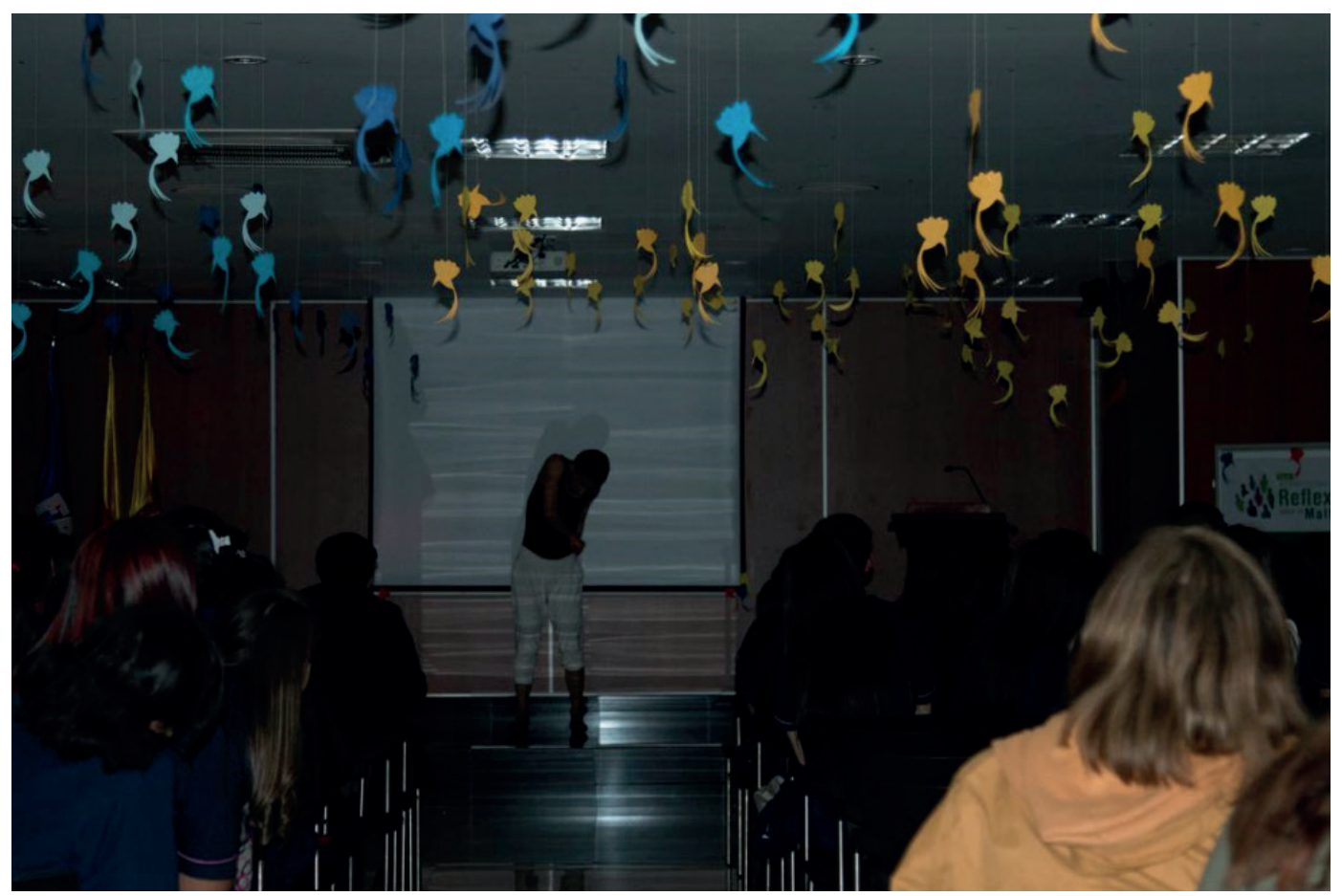

ii. Fase de co-creación comunitaria para el desarrollo de los insumos básicos de la herramienta audiovisual

Continuando con las actividades del proyecto, se desarrolló la fase de co-creación comunitaria, que dio comienzo a la materialización de los cortometrajes, en el proceso el objetivo era el desarrollo del storyline y del storyboard, que corresponden a la fase de preproducción y producción respectivamente. En la imagen 4 se observa una parte del proceso de tomas para el cortometraje. 
Figura 4. Pruebas de cámara, planos y tomas de la historia

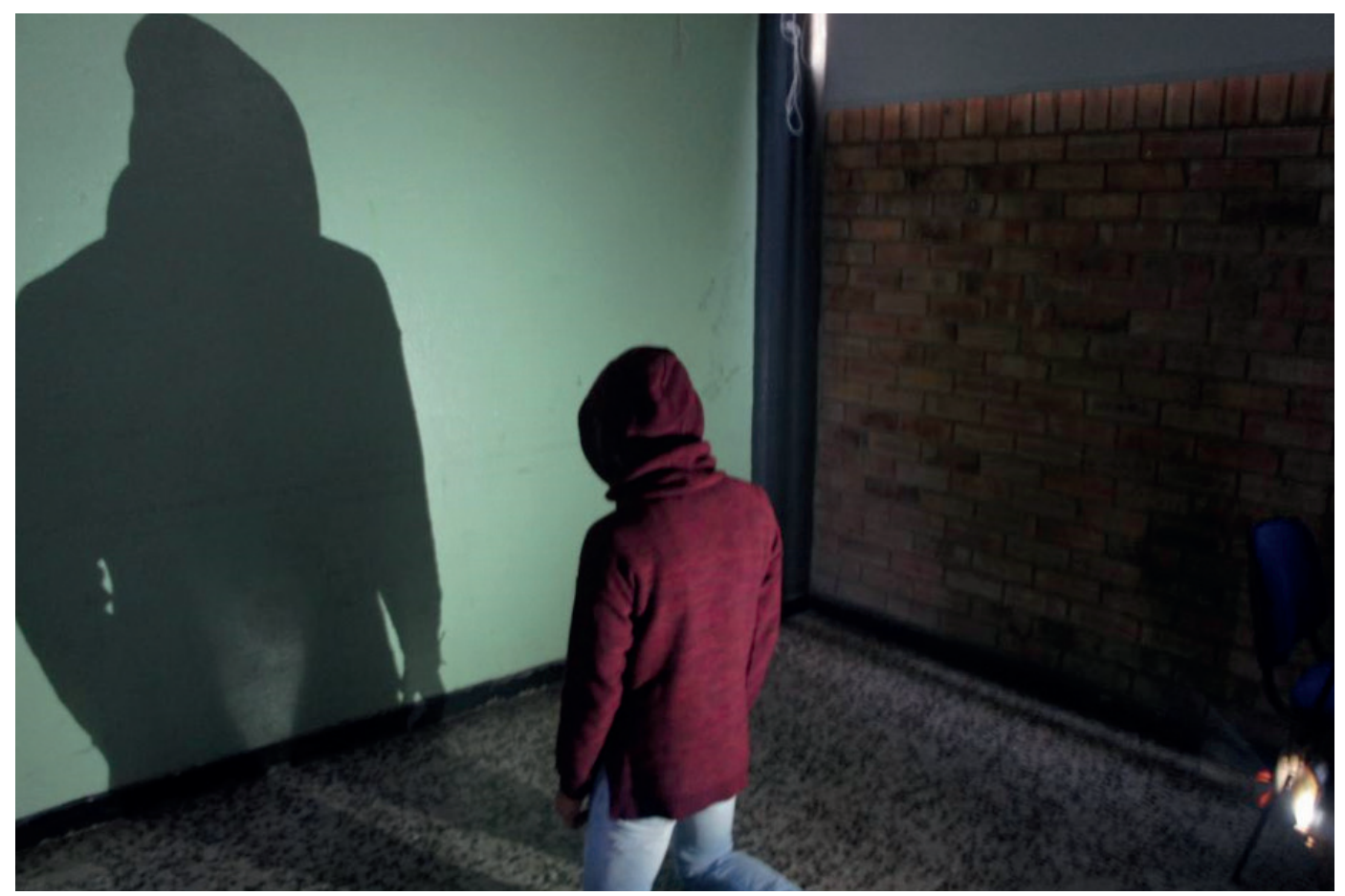

iii. Fase de desarrollo tecnológico de la herramienta audiovisual y socialización de la herramienta educativa audiovisual a los diversos grupos de interés

En esta fase el equipo del Programa de Producción Gráfica Publicitaria de la Fundación Tecnológica Autónoma de Bogotá, en cabeza del coordinador del Proyecto de FODESEP, a partir de las tomas de celulares suministradas por los estudiantes talleristas, desarrollan las piezas gráficas en su fase de post-producción y arreglos, socializando a los grupos de interés del Proyecto mediante la realización de una premier de estos cortometrajes; de manera que se permitiera apreciar el alcance de la reflexión y la investigación a partir de las piezas gráficas desarrolladas, como se puede apreciar en las imágenes 5 y 6 : 
Figura 5. Invitación a la premiere de los cortometrajes desarrollados

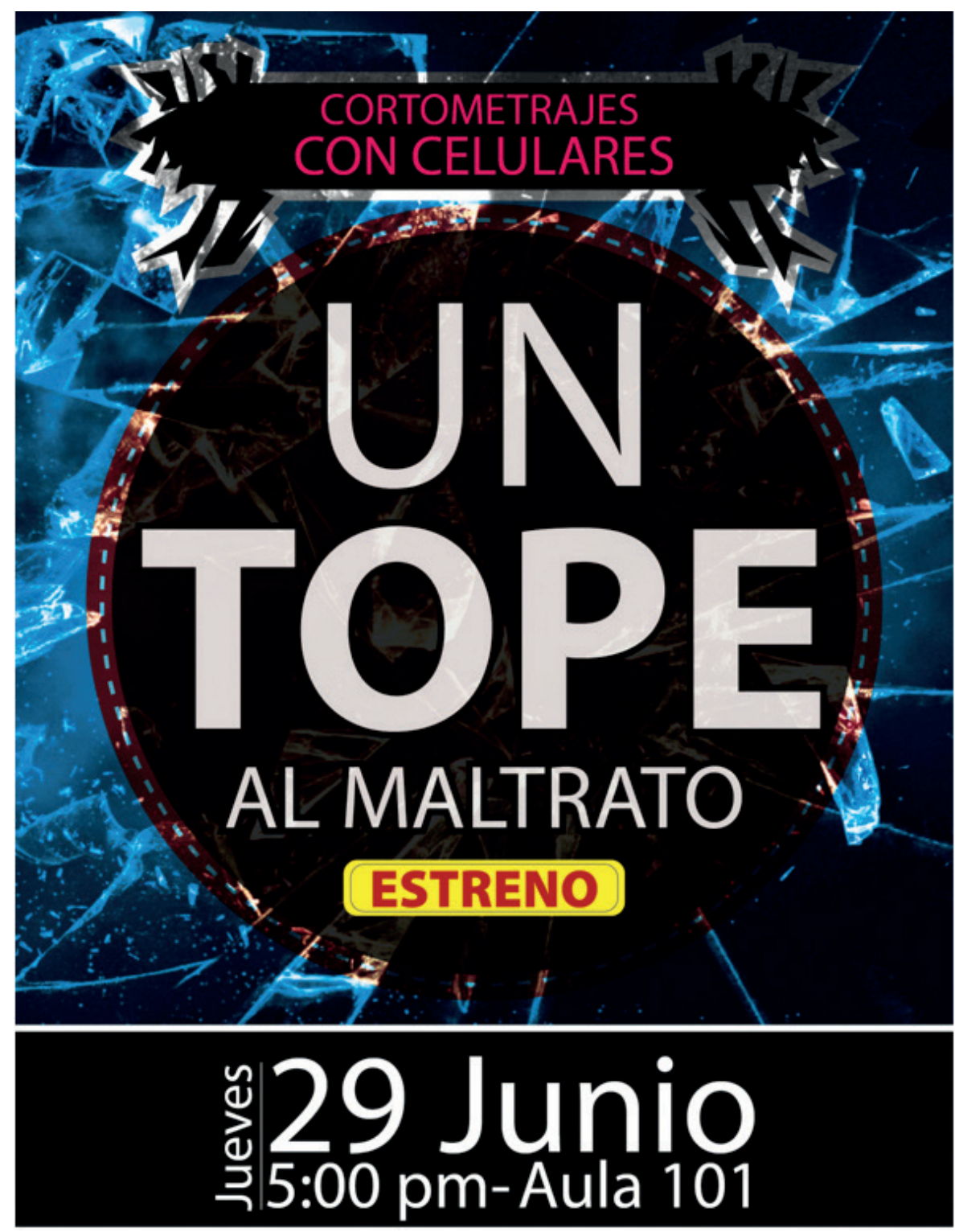


Figura 6. Invitaciones personalizadas para los asistentes al evento

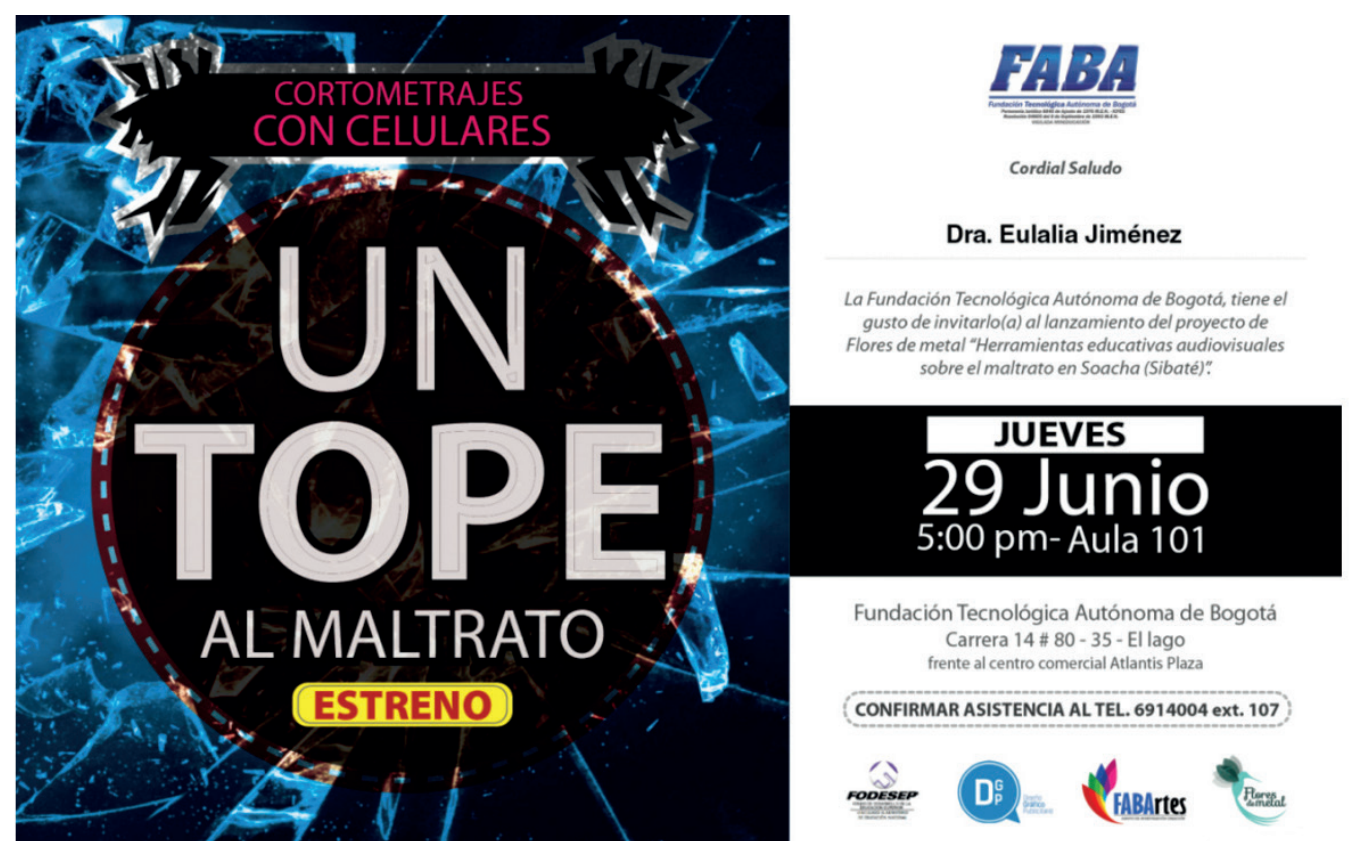

\section{Conclusiones}

A partir de la experiencia en investigación creación, se tuvieron como resultados principales: Tres cortometrajes realizados con celulares por los talleristas de la comunidad, realizando reflexión sobre el maltrato a la mujer. De acuerdo con Ecenarro (2012):

Como la tela del pintor en el acto de proponer, como diseñadores y formadores de futuros diseñadores, debemos propiciar nuevas maneras de mirar, de pensar, de imaginar, de proponer, corriéndonos de los prejuicios y formulaciones previas que tenemos sobre algo, apartándonos de la prefiguración del pensamiento a priori, a fin de poder hacer visible un nuevo mundo de sentidos (p. 38).

Se ha configurado un nuevo espacio de creación, una nueva "tela del pintor" dentro de las mentes de los participantes al taller y han podido construir desde su imaginario no sólo una reflexión, sino una reflexión audiovisual que permite refigurar nuevos escenarios de configuración multimedia desde sus propias realidades y sentimientos.

Desde la experiencia de investigación, los resultados fueron:

- La expectativa de los investigadores con respecto al acceso y participación de las comunidades fue excedida con entusiasmo y con creces, luego de múltiples dificultades y limitaciones operativas y presupuestarias que tuvieron que ser sorteadas en el desarrollo del trabajo. La acogida en todos los escenarios en que se presentó el proyecto ha sido siempre abrumadoras, ya que se esperaba inicialmente un grupo de 15 estudiantes y al final se trabajó con más de 50 participantes.

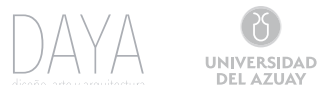


- Los participantes lograron capacitarse en procesos de creación y producción de cortometrajes, con elementos de fácil acceso.

- Lo anterior les permitió dialogar entre ellos sobre lo que significa el maltrato y asumir posturas críticas desde su visión abarcando experiencias comunitarias y referentes en lo familiar, comunitario, social.

- Los participantes identificaron diferentes situaciones de maltrato, que consideraron conexas con la situación del maltrato a la mujer, como lo son el maltrato a los seres vivos y a la naturaleza, en su propio municipio.

- Un elemento interesante de la reflexión consistió además en la transformación de la comunidad de estudiantes participantes. Muchos de ellos no consideraban posible que tuvieran la habilidad de desarrollar un cortometraje con sus conocimientos y herramientas a la mano. No solo lograron desarrollar los tres cortometrajes planeados, sino que además lograron transformar sus conocimientos y pensamientos sobre el maltrato en sí mismos y sus comunidades familiares.

- La participación activa de estudiantes, investigadores y comunidades brinda un panorama de esperanza

- Se establecieron puntos de partida para reflexiones sobre el maltrato en niños, animales, desde la sensibilización que fue creada con la experiencia.

- Los investigadores enriquecieron sus puntos de vista sobre el maltrato y la voz de los actores frente a esta situación, quedando grabada la experiencia para replicar en otros escenarios y futuros proyectos.

- Se amplió el conocimiento para la realización de proyectos de investigación-creación y una reflexión crítica sobre esta estrategia de desarrollo en la sociedad colombiana, donde estas iniciativas son escasas. - Se sentaron las bases de nuevos proyectos en donde la investigación-creación, la innovación social y los procesos de diseño están llamados a proponer desde una perspectiva diferente en los procesos de transformación de nuestras sociedades que tanto necesitamos en NuestrAmérica para lograr paz y justicia social.

\section{Agradecimientos}

Agradecimientos especiales a la Revista DAYA Diseño, Arte y Arquitectura de la Facultad de Diseño, Arquitectura y Arte de la Universidad del Azuay por permitir el espacio para la difusión de este artículo, a los financiadores del Proyecto FLORES DE METAL "Herramientas educativas audiovisuales sobre el maltrato a la mujer en el Municipio de Soacha": el Fondo para el Desarrollo de la Educación Superior (FODESEP) en cabeza de la Doctora Eulalia Nohemí Jiménez Rodríguez, al Doctor Reimundo Llanes Pelegrín y Nieves Lizcano Gamboa, al equipo de docentes e investigadores de la Fundación Tecnológica Autónoma de Bogotá y de la Universidad de Santander que de una u otra forma colaboraron en la realización de este proyecto, en especial al Diseñador Gráfico Camilo Villota Pascuaza y a Ana Emelis Obregón Flórez; junto con todos aquellos que han acompañado la creación y desarrollo del proyecto Flores de Metal desde sus inicios, por su continuo apoyo y contribuciones durante el desarrollo del proyecto. A los talleristas que participaron en la creación y realización de los productos audiovisuales por su entusiasmo y entrega, a nuestras familias y todos aquellos que hicieron posible el proyecto y este artículo a pesar de todas las dificultades y contratiempos.

\section{Limitaciones del estudio}

En este desarrollo no se muestran imágenes de los cortometrajes ni de los talleristas participantes, por tratarse de menores de edad. No obstante, se comparten las experiencias vividas como parte del proceso de investigación-creación y su finalidad principal, que es afinar las estrategias del diseño como medio para el cambio social. 


\section{Nota especial}

El presente artículo fue producto de la investigación realizada en el proyecto "Flores de metal - herramientas educativas audiovisuales en contra del maltrato a la mujer en el Municipio de Soacha" con fecha de Inicio Enero de 2017 y Finalización Junio de 2017 y desarrollado como antecedente de desarrollo y parte del proyecto institucional PCM - Desarrollo de estrategias para investigación creación como medio de producción en comunidad desde el diseño gráfico tecnológico y la innovación social, con fecha de Inicio: Agosto de 2018 Fin: Agosto de 2019, de la Fundación Tecnológica Autónoma de Bogotá - FABA.

\section{Referencias}

Agatón, Isabel del Carmen (2013). Justicia de género. Temis 2013.

Amnistía Internacional - IA (2002) Colombia: cuerpos marcados, crímenes silenciados: violencia sexual contra las mujeres en el marco del conflicto armado. Amnistía internacional.

Álvarez, Gustavo (2003). Las mujeres de la muerte. Grijalbo.

Dendaluce, I (1989). Aspectos Metodológicos de la Investigación Educativa. Narcea.

Díaz, José (2006). Memoria de las mujeres. Bogotá mesa de trabajo y conflicto armado de mujeres.

Ecenarro, G. (2012). Algunas reflexiones sobre la creatividad en las disciplinas proyectuales en un mundo lleno de imágenes e ideas. DAYA. Diseño, Arte YArquitectura., 1(1), 36 - 55. https:// doi.org/10.33324/daya.v1i1.6

Frascara, J. (2000). Diseño Gráfico y Comunicación. Ed. Infinito.

Gómez, R. (2009). Manual de Gestión de Proyectos. Ed. Universidad De Antioquia.

Hernandez Sampieri, R. Fernandez, C. \& Baptista, P. (2009). Metodología de la Investigación. Ed. McGraw Hill.

Ibáñez, J. (1988): Cuantitativo/Cualitativo, en Reyes R.: Terminología Científico-Social. Anthropos.

INMLCF - Instituto Nacional de Medicina Legal y Ciencias Forenses (2017). Reporte de violencia - Observatorio de violencia del INMLCF. http://www.medicinalegal.gov.co/observatorio-de-violencia

Koval, Santiago. (2011). Manual para la elaboración de trabajos académicos. Editorial Temas.

Lakatos, I. (1983). La Metodología de los Programas de Investigación Científica. Alianza.

Menacho, Chiok Luis Pedro (2006). Violencia y alcoholismo. Editorial Oriente.

ONU MUJERES (2019). Conferencias mundiales sobre la mujer. Sitio web de ONU Mujeres. http://www.unwomen.org/es/how-we-work/intergovernmental-support/world-conferences-on-women

Popper, K. (1962). La Lógica de la Investigación Científica. Tecnos.

Puello-Socarrás, G.E. \& Rodríguez Peña, A. (2017a). Revisión de las dinámicas de producción en investigación-creación de los programas de Diseño Gráfico en las IES en Colombia. WebPro, Tercera Edición, 40-63.

Puello-Socarrás, G.E. \& Rodríguez Peña, A. (2017b). Informe Final de proyecto: Flores de metal herramientas educativas audiovisuales en contra del maltrato a la mujer en el municipio de soacha". Fundación Tecnológica Autónoma de Bogotá. Bogotá: Fundación Tecnológica Autónoma de Bogotá. 
Rico, M. N. (1996). Violencia de género: un problema de derechos humanos (No. 16). Naciones Unidas Comisión Económica para América Latina y el Caribe (CEPAL).

Sastre, A. (2011). El proyecto de investigación Un mapa de ruta para el aprendiz de investigador. Ediciones USTA.

Suarez, P. (2006). Metodología de la Investigación. Diseños y Técnicas. Orión Editores Ltda.

Torres. C. A. (1996). Estrategias y Técnicas de Investigación Cualitativas. Facultad de Ciencias Sociales y Humanas. Editora Guadalupe Ltda.

WHO-OMS (2017). Violencia contra la mujer. Sitio web de la Organización Mundial de la Salud. https://www.who.int/es/news-room/fact-sheets/detail/violence-against-women 